\title{
Ageing impairs the $T$ cell response to dendritic cells
}

Article

Accepted Version

You, J., Dong, H., Mann, E., Knight, S. and Yaqoob, P. (2013) Ageing impairs the $T$ cell response to dendritic cells. Immunobiology, 218 (8). pp. 1077-1084. ISSN 0171-2985 doi: https://doi.org/10.1016/j.imbio.2013.02.002 Available at https://centaur.reading.ac.uk/32827/

It is advisable to refer to the publisher's version if you intend to cite from the work. See Guidance on citing.

To link to this article DOI: http://dx.doi.org/10.1016/j.imbio.2013.02.002

Publisher: Elsevier

All outputs in CentAUR are protected by Intellectual Property Rights law, including copyright law. Copyright and IPR is retained by the creators or other copyright holders. Terms and conditions for use of this material are defined in the End User Agreement.

\section{www.reading.ac.uk/centaur}

\section{CentAUR}

Central Archive at the University of Reading

Reading's research outputs online 


\section{Ageing impairs the $\mathbf{T}$ cell response to dendritic cells}

Subtitle: immune system and ageing

Jialu You ${ }^{1}$, Honglin Dong ${ }^{1}$, Elizabeth R. Mann ${ }^{2}$, Stella C. $\underline{\text { Knight }}^{2}$, Parveen $\underline{\text { Yaqoob }}^{1}$

${ }^{1}$ Department of Food and Nutritional Sciences, The University of Reading, Whiteknights PO Box 226, Reading RG6 6AP, UK.

${ }^{2}$ Antigen Presentation Research Group, Imperial College London, Northwick Park and St. Mark’s Campus, Harrow, HA1 3UJ, UK.

Corresponding author: Professor Parveen Yaqoob. Contact address: Department of Food and Nutritional Sciences, The University of Reading, Whiteknights PO Box 226, Reading RG6 6AP, UK. Phone: +44118 378 8720. Fax: +44(0)118931 0080. Email: p.yaqoob@reading.ac.uk.

Keywords: ageing, cytokine, dendritic cells, mixed leucocyte reaction, T cell activation

$\begin{array}{ll}\text { Abbreviations } & \\ \text { CCR } & \begin{array}{l}\text { C-C chemokine receptor type } \\ \text { dendritic cells }\end{array} \\ \text { DCs } & \text { foetal calf serum } \\ \text { FCS } & \text { forkhead box P3 } \\ \text { FoxP3 } & \text { low density cells } \\ \text { LDC } & \text { lipopolysaccharide } \\ \text { LPS } & \text { mixed leucocyte reaction } \\ \text { MLR } & \text { myeloid DCs } \\ \text { mDCs } & \text { peripheral blood mononuclear cell } \\ \text { PBMC } & \text { plasmacytoid DCs } \\ \text { pDCs } & \text { toll-like receptor } \\ \text { TLR } & \text { regulatory T cells } \\ \text { Treg } & \end{array}$




\section{Abstract}

Dendritic cells (DCs) are critical in priming adaptive T-cell responses, but the effects of ageing on interactions between DCs and T cells are unclear. This study investigated the influence of ageing on the maturation of and cytokine production by human blood-enriched DCs, and the impact on $\mathrm{T}$ cell responses in an allogeneic mixed leucocyte reaction (MLR). DCs from old subjects (65-75y) produced significantly less TNF- $\alpha$ and IFN- $\gamma$ than young subjects (20-30y) in response to lipopolysaccharide (LPS), but expression of maturation markers and co-stimulatory molecules was preserved. In the MLR, DCs from older subjects induced significantly restricted proliferation of young $\mathrm{T}$ cells, activation of $\mathrm{CD} 8^{+} \mathrm{T}$ cells and expression of IL-12 and IFN- $\gamma$ in T cells compared with young DCs. T cells from older subjects responded more weakly to DC stimulation compared with young T cells, regardless of whether the DCs were derived from young or older subjects. In conclusion, the capacity of DCs to induce $\mathrm{T}$ cell activation is significantly impaired by ageing. 


\section{Introduction}

Immunosenescence involves a progressive decline in immune function, which is associated with increased susceptibility to infections and poor response to vaccination. Many aspects of adaptive immunity are affected by ageing (Dunn-Walters, Banerjee et al. 2003; Swain, CliseDwyer et al. 2005; Frasca, Landin et al. 2008) . DCs play a central role in the priming of adaptive immune responses, but the influence of ageing on DC function remains poorly understood. Some studies demonstrate reduced numbers of both plasmacytoid and myeloid DCs (pDCs and mDCs) in the peripheral blood of older subjects (Shodell and Siegal 2002; Della Bella, Bierti et al. 2007; Perez-Cabezas, Naranjo-Gomez et al. 2007), but there is inconsistent data regarding the effects of ageing on DC phenotype and the ability of DCs to function as antigen presenting cells (Agrawal and Gupta 2011; Solana, Tarazona et al. 2012).

Induction of $\mathrm{T}$ cell responses by DCs involves the binding of antigen with major histocompatibility complex, DC expression of surface co-stimulatory molecules (e.g. CD40, CD80 and CD86), interaction with ligands on the T cell surface and production of cytokines. The efficacy of DCs in inducing $\mathrm{T}$ cell responses depends on a number of factors; impaired maturation of DCs, or altered cytokine production are likely to have a knock-on effect on the T-cells that they stimulate. To date, data regarding the influence of ageing on human DC expression of co-stimulatory molecules and cytokine production, in response to in vitro maturation-inducing stimuli, has been inconsistent, showing either comparable or reduced DC function in the elderly (Lung, Saurwein-Teissl et al. 2000; Pietschmann, Hahn et al. 2000; Saurwein-Teissl, Romani et al. 2000; Shurin, Shurin et al. 2007).

It is not clear whether DCs from young subjects are able to overcome the impaired responsiveness of $\mathrm{T}$ cells from older subjects and human studies investigating this are very limited (Agrawal, Agrawal et al. 2007; Jiang, Fisher et al. 2011). Lung, Saurwein-Teissl et al. (2000) demonstrated that human monocyte-derived DCs from young and older subjects were 
equally effective in stimulating proliferation of and cytokine secretion by influenza-specific $\mathrm{CD}^{+} \mathrm{T}$ cells. In contrast, Agrawal, Agrawal et al. (2007) demonstrated that monocytederived DCs from older people were defective in stimulating proliferation of $\mathrm{CD}^{+}$naïve $\mathrm{T}$ cells from young subjects.

The aim of the present study was to investigate the influence of ageing on the maturation of and cytokine production by human blood-enriched DCs, and to investigate whether these age-induced alterations have an impact on DC and T cell responses in the MLR. By avoiding the use of cell lines and long cultures with addition of cytokines and growth factors, this represents a novel approach to study the influence of ageing on both DC and T cell function.

\section{Materials and Methods}

\subsection{Peripheral blood mononuclear cell (PBMC) preparation and culture}

Peripheral blood was obtained from healthy young (20-30y) and older (65-75y) subjects. Exclusion criteria included diabetes requiring medication, asplenia and other acquired or congenital immunodeficiencies, any autoimmune disease, malignancy, cirrhosis, connective tissue diseases; current use of immunomodulating medication (including oral prednisone and inhaled steroids), self-reported symptoms of acute or recent infection, use of antibiotics within last 3 months, alcoholism and drug misuse (University of Reading Ethics Committee project ref 10/05). Blood was diluted into an equal volume of RPMI 1640 medium. PBMCs were isolated by density gradient centrifugation over Ficoll-Paque (Fisher Scientific, UK), and resuspended in RPMI 1640 medium with 10\% foetal calf serum (FCS, Sigma Ltd, UK). PBMCs were cultured overnight in culture flasks $\left(2 \times 10^{7}\right.$ cells/flask $)$ in a $37^{\circ} \mathrm{C}, 5 \% \mathrm{CO}_{2}$ atmosphere.

\subsection{Human blood DC enrichment and culture}


Low Density Cells (LDCs) were prepared as the source of human blood-enriched DCs (which normally represent $1-2 \%$ of PBMCs). The LDCs had morphological characteristics of DCs, as described in previous studies (Knight, Farrant et al. 1986; Kerdiles, Stone et al. 2010), typically $98-100 \%$ HLA-DR positive and stimulate strong proliferation of allogeneic T-cells at very low concentrations (Knight, Farrant et al. 1986; Holden, Bedford et al. 2008). Since DCs are unique in their ability to generate primary $\mathrm{T}$-cell responses, T-cell responses generated in the MLR were interpreted as a result of DC stimulation. Unlike monocytederived DCs, homing markers are not altered during culture of LDCs, which is an advantage (Mann, Bernardo et al. 2012).

After overnight culture of PBMC, the non-adherent cells were collected and centrifuged over Nycoprep (500 x g, 15min) (PROGEN Biotechnik GmbH). LDCs were removed from the interface, washed twice (650 x g, $5 \mathrm{~min}$ ) in RPMI 1640 medium with $10 \%$ FCS and resuspended in the same medium.

LDCs were adjusted to a concentration of $1 \times 10^{6}$ cells $/ \mathrm{ml}$ and cultured in the presence or absence of $10 \mu \mathrm{g} / \mathrm{ml} \mathrm{LPS}$ in a $37^{\circ} \mathrm{C}, 5 \% \mathrm{CO}_{2}$ atmosphere for $24 \mathrm{~h}$ (see Fig. 1).

\section{3. $T$ cell purification and $D C$ stimulation of $T$ cells}

In this allogeneic MLR, T cells were obtained from blood donated by healthy young or older subjects, which were different from the DC donors. After isolating PBMCs, T cells were separated by negative isolation using a Human T cell enrichment kit (BD Bioscience, UK). The purity of $\mathrm{T}$ cells after this selection process was higher than $98 \%$, as determined by CD3 antibody staining. Prior to culture, purified T cells were labelled with carboxyfluorescein diacetate succinimidyl ester (CFSE, Invitrogen Ltd, UK) for subsequent assessment of T cell proliferation. $\mathrm{T}$ cells $\left(4 \times 10^{5}\right)$ from young and older subjects were co-incubated with $3 \%$ cultured LDCs from young and older subjects in a $37^{\circ} \mathrm{C}, 5 \% \mathrm{CO}_{2}$ atmosphere for $5 \mathrm{~d}$, using the experimental design illustrated in Fig. 1. 


\subsection{Intracellular cytokine production}

Intracellular cytokine production by DCs following $24 \mathrm{~h}$ incubation in the presence or absence of LPS, or by T cells following the MLR was analysed using flow cytometry. Cells were incubated with or without $50 \mu 1$ Monensin $(3 \mu \mathrm{M})(\mathrm{eBioscience} \mathrm{Ltd}, \mathrm{UK})$ in a $37^{\circ} \mathrm{C}, 5 \% \mathrm{CO}_{2}$ atmosphere for $4 \mathrm{~h}$, washed in FACS buffer (BD Bioscience, UK) and stained with the appropriate surface marker antibodies before fixation, permeabilisation and staining with appropriate antibodies for intracellular cytokines.

\subsection{Antibody staining}

For identification and characterization of peripheral blood DCs, cultured LDCs were stained with HLA-DR (APC, PerCP-Cy 5.5 or PE) and with a lineage cocktail containing antiCD3, CD14, CD19, CD20 (FITC). Cells that were negative to the cocktail but positive to HLA-DR were identified as DCs (see Fig. 2A). On average, 93\% of LDCs were Lin ${ }^{-H L A}-\mathrm{DR}^{+}$. This was used in conjunction with antibodies for maturation markers (CD80 (PE-Cy 7), CD86 (APC) and CD40 (APC-Cy 7)), or a migration marker, C-C chemokine receptor type7 (CCR7) (PerCP-Cy 5.5). Cultured T cells were identified by CD3 (PE-Cy 7, APC or APC-Cy 7) staining (see Fig. 2B) and classified into CD4 (PE-Cy 7) and CD8 (PerCP-Cy 5.5) subsets. CD25 (APC) was used as a marker for T cell activation; and integrin $\beta 7$ (PE) as a homing marker. Antibodies against IL-10 (PE), IL-12 (PE), TNF- $\alpha$ (PerCP-Cy 5.5), IFN- $\gamma$ (APC-Cy 7) and TGF- $\beta$ (PE-Cy 7) were used to assess intracellular cytokine production by Lin HLA$\mathrm{DR}^{+} \mathrm{DCs}$ or DC-stimulated $\mathrm{CD}^{+} \mathrm{T}$ cells. Isotype-matched control antibodies included rat IgG2a (PE), mouse IgG1 (FITC, PE, PE-Cy 7, PerCP-Cy 5.5, APC-Cy 7), mouse IgG2a (PerCP-Cy 5.5) and mouse IgG2b (PerCP-Cy 5.5). Stained cells were incubated at room temperature in the dark for 30-45min, washed twice, resuspended in Fix solution and kept at $4^{\circ} \mathrm{C}$ until analysis by flow cytometry. The lineage cocktail, CD80, HLA-DR (APC), CD3 
(APC-Cy 7), CD25, IL-10, IL-12 and rat IgG2a were obtained from BD Biosciences, and all other antibodies were purchased from Cambridge Bioscience Ltd., UK.

\subsection{Flow cytometric analysis}

Samples were analysed using a FACSCanto II flow cytometer (BD, UK). Data were analysed by superenhanced Dmax (SED) normalised subtraction using FlowJo software.

\subsection{Statistical analysis}

Statistical analysis was performed using Mini Tab 16.0. Data were tested for normality and transformed using the Johnson Transformation where appropriate. Significant differences (P $<0.05)$ were evaluated by the Student's t-test or two-way ANOVA using the General Linear Model, followed by appropriate post-hoc tests with Bonferroni correction. All data are shown as mean $\pm \mathrm{SE}$ (standard error).

\section{Results}

\subsection{Ageing impairs cytokine production by DCs, but not surface marker expression}

DCs in LDC preparations from human blood were identified as HLA-DR ${ }^{+}$and negative for a lineage cocktail containing CD3, CD14, CD19 and CD20 antibodies (Figure 2A). The proportion of DCs was similar in the young and older subjects. Cell surface expression of CD80, CD40 and CCR7, but not CD86, were significantly up-regulated after conditioning with LPS (Fig. 3). None of the surface markers, or their up-regulation by LPS, were affected by ageing (Fig. 3).

There were significant effects of ageing on LPS-induced production of TNF- $\alpha$ and IFN- $\gamma$ by DCs (Fig. 4). LPS induced production of TNF- $\alpha$ and IFN- $\gamma$ in DCs from the young subjects only; DCs from the older subjects were unresponsive (Fig. 4). It was notable that IFN- $\gamma$ production by unstimulated DCs from older subjects was higher than that from young 
subjects (Fig. 4). LPS induced production of IL-10, IL-12 and TGF- $\beta$ to a similar degree in young and older DCs data not shown.

\subsection{Influence of ageing on DC-induced activation of $T$ cells}

LPS/DC-induced T cell proliferation was significantly affected by the age of both the DCs and the $\mathrm{T}$ cells (Fig. 5). In MLR, the highest rate of proliferation was observed when DCs from young subjects were co-incubated with T cells from young subjects (Fig. 5). When LPSstimulated DCs from young subjects were co-incubated with T cells from older subjects, proliferation was significantly reduced (Fig. 5). DCs from older subjects exhibited a poor ability to induce proliferation of $\mathrm{T}$ cells, regardless of whether the $\mathrm{T}$ cells were donated by young or older subjects (Fig. 5).

Activation of young and old T cells in the MLR was assessed by expression of CD25 on $\mathrm{CD}^{+}$and $\mathrm{CD}^{+} \mathrm{T}$ cells (Fig. 6). Exposure of young T cells to either unstimulated DCs or LPS-stimulated DCs increased expression of CD25, but there was no response of $\mathrm{T}$ cells from older subjects; this was the case for both $\mathrm{CD}^{+}$and $\mathrm{CD}^{+} \mathrm{T}$ cell populations (Fig. 6). The effects of ageing were particularly notable for the $\mathrm{CD}^{+} \mathrm{T}$ cells, where induction of CD25 expression by young $\mathrm{CD}^{+} \mathrm{T}$ cells was significantly greater if the LPS-stimulated DCs were donated by young subjects (Fig. 6). It was also notable that neither young DCs nor older DCs were able to induce $\mathrm{CD} 25$ expression on older $\mathrm{CD}^{+} \mathrm{T}$ cells, indicating significant unresponsiveness of $\mathrm{CD}^{+} \mathrm{T}$ cells from older subjects in the MLR (Fig. 6).

\subsection{Influence of ageing on DC-induced homing ability of $\mathrm{T}$ cells}

Expression of integrin $\beta 7$ confers gut-homing ability (Wagner, Lohler et al. 1996; Agace, Higgins et al. 2000). Although there was a greater proportion of integrin $\beta 7^{+}$older T cells at baseline, LPS-stimulated DCs upregulated integrin $\beta 7$ expression by young T cells, but not by older T cells (Fig. 7), suggesting impaired responsiveness of older T cells to DC priming (Fig. 7). 


\subsection{Ageing impairs production of IL-12 and TGF- $\beta$ by $T$ cells in the MLR}

Unstimulated T cells from old subjects produced significantly higher levels of IFN- $\gamma$ than that from young subjects, but production of TNF- $\alpha$, IL-12, TGF- $\beta$ and IL-10 by unstimulated T cells was not different between the two age groups (Fig. 8). All of the cytokines, except for IFN- $\gamma$, were inducible by DC stimulation; however DCs induced IL-12 and TGF- $\beta$ production by young $\mathrm{T}$ cells only (Fig. 8). In contrast, IL-10 production by old $\mathrm{T}$ cells stimulated with DCs was significantly greater than that of young T cells (Fig. 8).

There was little difference in the capacity of young vs old DCs to induce production of cytokines by T cells, with the exception of IL-12 production in DC-stimulated old T cells and IFN- $\gamma$ expression on young T cells treated with LPS-stimulated DCs being greater when DCs were derived from young subjects (Fig. 8).

\section{Discussion}

This study demonstrates that cytokine production by DC and the capacity of DCs to trigger T cell responses in the MLR are significantly impaired by ageing. The use of blood-enriched DCs (LDCs) avoids the long culture period and the conditions required for in vitro differentiation and the ability of LDCs to participate in MLRs has been demonstrated previously (Knight, Farrant et al. 1986; Holden, Bedford et al. 2008). In the current study, the expression of the co-stimulatory molecules, CD40 and CD80, by unstimulated DCs was comparable in young and old subjects, suggesting that ageing has little influence on the maturation of DCs in healthy older subjects; this is consistent with several other studies (Steger, Maczek et al. 1996; Pashenkov, Kouwenhoven et al. 2000; Agrawal, Agrawal et al. 2007; Della Bella, Bierti et al. 2007; Pereira, Duarte de Souza et al. 2011; Tan, Cavanagh et al. 2012). The response to LPS was also preserved to some extent during ageing, consistent with the studies of Agrawal, Agrawal et al. (2007) and Ciaramella, Spalletta et al. (2011), 
who used monocyte-derived DCs. Furthermore, although Della Bella, Bierti et al. (2007) demonstrated greater maturation status of circulating DCs in older subjects, there was a comparable response to LPS of DCs from young and older subjects. Some studies reported reduced expression of co-stimulatory molecules and cytokine production in frail elderly subjects (Uyemura, Castle et al. 2002), suggesting that health status might play a role in ageassociated changes in DC function. The ability of DCs to migrate to secondary lymph nodes to elicit appropriate $\mathrm{T}$ and $\mathrm{B}$ cell mediated responses following the capture of antigen is critical and requires expression of CCR7 (Steger, Maczek et al. 1996; Linton, Li et al. 2005; Toapanta and Ross 2009). The current study suggests that CCR7 expression is preserved during ageing; this was also observed by Agrawal, Agrawal et al. (2007) using monocytederived DCs.

Impairment of $\mathrm{T}$ cell activation by ageing $\mathrm{DCs}$ has been suggested to contribute to immunosenescence (Pereira, Duarte de Souza et al. 2011). In the current study, the greatest rate of $\mathrm{T}$ cell proliferation was observed in young $\mathrm{T}$ cells stimulated by young LPSstimulated DCs. Older LPS-stimulated DCs were unable to induce proliferation to the same extent in young $\mathrm{T}$ cells. There is little comparative data in the literature, but Agrawal, Agrawal et al. (2007) demonstrated that monocyte-derived DC-induced proliferation of CD4 ${ }^{+}$ naïve $\mathrm{T}$ cells was impaired when the DCs were derived from older subjects. In contrast, Steger, Maczek et al. (1996) demonstrated no impairment of the ability of human peripheral blood mononuclear cell-derived DCs from older subjects to stimulate T cell lines. The use of cell lines may be a critical methodological difference contributing to the difference in outcome. A novel aspect of the current study was the use of either young or old human T cells in the MLR. In the current study, LPS/DCs induced the proliferation of older T cells to a lower degree than young T cells, even when DCs were derived from young subjects. Such intrinsic defects in responsiveness of aged $\mathrm{T}$ cells to antigen have been reported in an 
allogeneic MLR model using murine myeloid bone marrow-derived DCs (Tesar, Walker et al. 2006). Overall, this suggests that both DC and T-cell function are affected by ageing.

It is notable that in the current study, activation of $\mathrm{CD} 8^{+}$cytotoxic $\mathrm{T}$ cells in young subjects by LPS-stimulated DCs was preferentially impaired; $\mathrm{CD}^{+} \mathrm{T}$ cells remained relatively unaffected by ageing of DCs However, Agrawal, Agrawal et al. (2007) demonstrated age-related impairment of proliferation of influenza specific $\mathrm{CD}^{+} \mathrm{T}$ cells by monocyte-derived DCs; the reasons for this are unclear, but may be related to differences in cell type and stimulus. In general, ageing results in a greater diminution and dysregulation of circulating $\mathrm{CD}^{+}$naïve T cells (Ferrando-Martinez, Ruiz-Mateos et al. 2011), greater loss of telomerase activity following pathogen stimulation (Valenzuela and Effros 2002), and greater age-associated changes in TNF- $\alpha$ secretion by $\mathrm{CD}^{+} \mathrm{T}$ cells than their $\mathrm{CD} 4^{+}$counterparts (Schindowski, Fröhlich et al. 2002). Although the mechanisms underlying the greater impairment of $\mathrm{CD}^{+} \mathrm{T}$ cell responsiveness to DCs in the current study are not clear, it is reasonable to suggest that decreased TNF- $\alpha$ production by DCs may be involved (Liu, Nahar et al. 2012).

Pereira, Duarte de Souza et al. (2011) suggested that T cell defects during ageing were related to multiple alterations on aged DCs. In the current study, ageing reduced production of TNF- $\alpha$ and IFN- $\gamma$ by DCs in response to LPS stimulation. This has potentially important implications, since reduced TNF- $\alpha$ and IFN- $\gamma$ production by plasmacytoid DCs from older subjects, caused by defects in TLR signalling, is associated with an inability to generate an effective antibody response to influenza vaccination (Panda, Qian et al. 2010). A role for TNF- $\alpha$ in DC-induced T cell proliferation is also evident from clinical data suggesting poor stimulation of $\mathrm{T}$ cell activity by DCs from rheumatoid arthritis patients treated with antiTNF- $\alpha$ antibodies (Baldwin, Ito-Ihara et al. 2010; Liu, Nahar et al. 2012). Thus, impaired 
production of TNF- $\alpha$ and IFN- $\gamma$ by older DCs could result in a weak response to vaccination and contribute to the dysregulation of DC-induced T cell proliferation in elderly subjects. However, the literature is not entirely consistent with respect to the effects of ageing on overall DC cytokine secretion profiles (Lung, Saurwein-Teissl et al. 2000; Wong, Magnusson et al. 2010) (Agrawal, Agrawal et al. 2007; Agrawal, Tay et al. 2009) (Della Bella, Bierti et al. 2007; Panda, Qian et al. 2010; Ciaramella, Spalletta et al. 2011). It is likely that the use of different stimuli (e.g. influenza virus, TLR agonists, self-DNA, LPS), species, methodology (e.g. intracellular vs secreted cytokines) and source of DCs may account for at least some of the inconsistency.

The current study demonstrated that although LPS-stimulated IFN- $\gamma$ production by older DCs was impaired, basal production of IFN- $\gamma$ by older DCs was higher than young subjects. An ageing-associated increase in IFN- $\gamma$ has previously been reported (Sakata-Kaneko, Wakatsuki et al. 2000; Lio, Scola et al. 2002) and is suggested to contribute to the phenomenon of 'inflamm-ageing' (Fridman and Tainsky 2008), although there is little data on the influence of ageing on basal IFN- $\gamma$ production by circulating DCs. The data herein suggests that DCs might contribute to the systemic accumulation of IFN- $\gamma$ associated with ageing.

Since co-culture of young DCs with young $\mathrm{T}$ cells resulted in the greatest rate of proliferation and activation of $\mathrm{T}$ cells, it was expected that the worst combination would be old DCs and old T cells. However, this was not the case; young DCs were equally poor at stimulating old T cells as were old DCs, suggesting that intrinsic defects in T cells outweigh the impact of ageing DCs. The literature is not clear on whether impaired T-cell responses during ageing are exclusively due to intrinsic defects or influenced by ageing of DCs. Experiments involving transfer of young/old murine $\mathrm{T}$ cells to young/old recipients demonstrated that age-related impairment of T-cell activation was mainly due to intrinsic $\mathrm{T}$ - 
cell defects and not critically dependent on the ageing of antigen-presenting cells (Tesar, Walker et al. 2006). However, a recent study suggested that reduced function of aged $\mathrm{T}$ cells was intimately related with impairment of DC function (Pereira, Duarte de Souza et al. 2011). The current study supports the former view.

The most dramatic effects of ageing on cytokine production by T cells in the MLR were for IL-12, TGF- $\beta$ and IL-10. IL-12 production by older T cells was significantly lower than that by young T cells, and the capacity of older DCs to induce IL-12 production by older T cells was reduced compared to that of young DCs. As a result, ageing of both DCs and T cells resulted in impaired IL-12 production in the MLR. DC-induced TGF- $\beta$ production by T cells was significantly impaired by ageing, but the defect appeared to reside primarily within $\mathrm{T}$ cells, since the ability of older DCs to induce TGF- $\beta$ production by young T cells was preserved. In contrast to IL-12 and TGF- $\beta$, IL-10 production by older T cells in response to DC stimulation was augmented compared with that by young $\mathrm{T}$ cells, regardless of whether the DCs were derived from young or older subjects. It is noteworthy that pre-stimulation of DCs with LPS did not further increase IL-10 production by older T cells, which is suggestive of a defect in TLR-dependent immunity. It has been suggested that high production of IL-10 in the elderly indicates development of immune deficiency (Gregg, Smith et al. 2005) and is associated with a weak response to influenza vaccination (Corsini, Vismara et al. 2006). However, the impact of ageing on $\mathrm{T}$ cell immunity is complex and may involve defects in cell activation, co-stimulatory signalling and intracellular signalling pathways. Further studies are required to understand the selective nature of the effects of ageing on DC-induced T cell activation.

The $\beta 7$ integrin family plays an important role in the homing of $\mathrm{T}$ lymphocytes to the gastrointestinal mucosa, and this study shows, for the first time, that $\mathrm{T}$ cells from older 
subjects were unresponsive to upregulation of integrin $\beta 7$ by DCs. This has potentially important implications, as it is indicative of reduced T-cell migration to intestinal sites, and therefore mucosal immunity (Gorfu, Rivera-Nieves et al. 2009), and may play a role in the greater susceptibility of older individuals to gut-related infections and gastroenteritis (Gavazzi and Krause 2002; Hébuterne 2003). Interestingly, unstimulated T cells from the older subjects expressed significantly higher levels of integrin $\beta 7$ than the young subjects. It could be speculated that greater trafficking of $\mathrm{T}$ cells to the intestine could increase the risk of inflammatory disease in older individuals in normal non-pathogenic conditions (Aranda, Sydora et al. 1997; Souza, Elia et al. 1999; Sydora, Wagner et al. 2002).

\section{Conclusions}

In summary, DC maturation in response to LPS was maintained to some degree during ageing, but the capacity to induce T-cell activation was significantly impaired. This work highlights the challenges associated with developing therapeutic agents for immunosenescence, the impact of which is clearly complex and far-reaching. Finally, it demonstrates that the age of the DC and $\mathrm{T}$ cell donor is a critical factor in determining the outcome of the MLR, and emphasizes the importance of stringent controls for age.

\section{Acknowledgements}

This work was funded by the Biotechnology and Biological Sciences Research Council's

Diet and Health Research Industry Club (BBSRC-DRINC), UK (grant number $\mathrm{BB} / \mathrm{H} 00470 \mathrm{X} / 1)$. 


\section{Reference}

Agace, W. W., J. M. Higgins, et al. (2000). "T-lymphocyte-epithelial-cell interactions: integrin alpha(E)(CD103)beta(7), LEEP-CAM and chemokines." Curr. Opin. Cell. Biol. 12(5): 563-568.

Agrawal, A., S. Agrawal, et al. (2007). "Altered innate immune functioning of dendritic cells in elderly humans: A role of phosphoinositide 3-kinase-signaling pathway." J. Immunol. 178(11): 69126922.

Agrawal, A., S. Agrawal, et al. (2007). "Dendritic cells in human aging." Exp. Gerontol. 42(5): 421-426.

Agrawal, A. and S. Gupta (2011). "Impact of aging on dendritic cell functions in humans." Ageing Res. Rev. 10(3): 336-345.

Agrawal, A., A. Tay, et al. (2009). "Increased Reactivity of Dendritic Cells from Aged Subjects to SelfAntigen, the Human DNA." J. Immunol. 182(2): 1138-1145.

Aranda, R., B. C. Sydora, et al. (1997). "Analysis of intestinal lymphocytes in mouse colitis mediated by transfer of CD4+, CD45RBhigh T cells to SCID recipients." J. Immunol. 158(7): 3464-3473.

Baldwin, H. M., T. Ito-Ihara, et al. (2010). "Tumour necrosis factor alpha blockade impairs dendritic cell survival and function in rheumatoid arthritis." Ann. Rheumatic Dis. 69: 1200-12007.

Ciaramella, A., G. Spalletta, et al. (2011). "Effect of age on surface molecules and cytokine expression in human dendritic cells." Cell. Immunol. 269(2): 82-89.

Corsini, E., L. Vismara, et al. (2006). "High interleukin-10 production is associated with low antibody response to influenza vaccination in the elderly." J. Leukocyte Biol. 80(2): 376-382.

Della Bella, S., L. Bierti, et al. (2007). "Peripheral blood dendritic cells and monocytes are differently regulated in the elderly." Clin. Immunol. 122(2): 220-228.

Dunn-Walters, D. K., M. Banerjee, et al. (2003). "Effects of age on antibody affinity maturation." Biochem. Soc.T. 31: 447-448.

Ferrando-Martinez, S., E. Ruiz-Mateos, et al. (2011). "Age-related deregulation of naive T cell homeostasis in elderly humans." Age 33(2): 197-207.

Frasca, D., M. Landin, et al. (2008). "Aging down-regulates the transcription factor E2A, activationinduced cytidine deaminase, and Ig class switch in human B cells." J. Immunol. 180(8): 52835290.

Fridman, A. L. and M. A. Tainsky (2008). "Critical pathways in cellular senescence and immortalization revealed by gene expression profiling." Oncogene 27(46): 5975-5987.

Gavazzi, G. and K.-H. Krause (2002). "Ageing and infection." The Lancet Infectious Dis. 2(11): 659-666.

Gorfu, G., J. Rivera-Nieves, et al. (2009). "Role of beta7 integrins in intestinal lymphocyte homing and retention." Curr. Mol. Med. 9(7): 836-850.

Gregg, R., C. M. Smith, et al. (2005). "The number of human peripheral blood CD4(+) CD25(high) regulatory T cells increases with age." Clin. Exp. Immunol. 140(3): 540-546.

Hébuterne, X. (2003). "Gut changes attributed to ageing: effects on intestinal microflora." Curr. Opin. Clin. Nutr. Metab. Care 6(1): 49-54.

Holden, N. J., P. A. Bedford, et al. (2008). "Dendritic cells from control but not atopic donors respond to contact and respiratory sensitizer treatment in vitro with differential cytokine production and altered stimulatory capacity." Clin Exp Allergy 38(7): 1148-1159.

Holden, N. J., P. A. Bedford, et al. (2008). "Dendritic cells from control but not atopic donors respond to contact and respiratory sensitizer treatment in vitro with differential cytokine production and altered stimulatory capacity." Clin. Exp. Allergy 38: 1148-1159.

Jiang, J., E. M. Fisher, et al. (2011). "CD8 T cell responses to influenza virus infection in aged mice." Ageing Research Reviews 10(4): 422-427.

Kerdiles, Y. M., E. L. Stone, et al. (2010). "Foxo Transcription Factors Control Regulatory T Cell Development and Function." Immunity 33(6): 890-904.

Knight, S. C., J. Farrant, et al. (1986). "Nonadherent, low-density cells from human peripheral-blood contain dendritic cells and monocytes, both with veiled morphology." Immunol. 57(4): 595603. 
Linton, P. J., S. K. P. Li, et al. (2005). "Intrinsic versus environmental influences on T-cell responses in aging." Immunol. Rev. 205: 207-219.

Lio, D., L. Scola, et al. (2002). "Allele frequencies of +874 T $\rightarrow$ A single nucleotide polymorphism at the first intron of interferon-gamma gene in a group of Italian centenarians." Exp. Gerontol. 37(2-3): 315-319.

Liu, W. M., T. E. R. Nahar, et al. (2012). "Impaired production of TNF- $\alpha$ by dendritic cells of older adults leads to a lower CD8+ T cell response against influenza." Vaccine 30(9): 1659-1666.

Lung, T. L., M. Saurwein-Teissl, et al. (2000). "Unimpaired dendritic cells can be derived from monocytes in old age and can mobilize residual function in senescent T cells." Vaccine 18(16): 1606-1612.

Mann, E. R., D. Bernardo, et al. (2012). "Human gut-specific homeostatic dendritic cells are generated from blood precursors by the gut microenvironment." Inflammatory Bowel Diseases 18(7): 1275-1286.

Panda, A., F. Qian, et al. (2010). "Age-Associated Decrease in TLR Function in Primary Human Dendritic Cells Predicts Influenza Vaccine Response." J. Immunol. 184(5): 2518-2527.

Pashenkov, M., M. C. M. Kouwenhoven, et al. (2000). "Phenotypes and cytokine profiles of enriched blood dendritic cells in healthy individuals." Eur. Cytokine Netw. 11(3): 456-463.

Pereira, L. F., A. P. Duarte de Souza, et al. (2011). "Impaired in vivo CD4+ T cell expansion and differentiation in aged mice is not solely due to $T$ cell defects: Decreased stimulation by aged dendritic cells." Mechanisms of Ageing and Development 132(4): 187-194.

Pereira, L. F., A. P. Duarte de Souza, et al. (2011). "Impaired in vivo CD4+ T cell expansion and differentiation in aged mice is not solely due to T cell defects: Decreased stimulation by aged dendritic cells." Mech. Ageing Dev. 132(4): 187-194.

Perez-Cabezas, B., M. Naranjo-Gomez, et al. (2007). "Reduced numbers of plasmacytoid dendritic cells in aged blood donors." Exp. Gerontol. 42(10): 1033-1038.

Pietschmann, P., P. Hahn, et al. (2000). "Surface markers and transendothelial migration of dendritic cells from elderly subjects." Experimental Gerontology 35(2): 213-224.

Sakata-Kaneko, S., Y. Wakatsuki, et al. (2000). "Altered Th1/Th2 commitment in human CD4(+) T cells with ageing." Clin. Exp. Immunol. 120(2): 267-273.

Saurwein-Teissl, M., N. Romani, et al. (2000). "Dendritic cells in old age-neglected by gerontology?" Mech. Ageing Dev. 121(1-3): 123-130.

Schindowski, K., L. Fröhlich, et al. (2002). "Age-related impairment of human T lymphocytes' activation: specific differences between CD4+ and CD8+ subsets." Mech. Ageing Dev. 123(4): 375-390.

Shodell, M. and F. P. Siegal (2002). "Circulating, interferon-producing plasmacytoid dendritic cells decline during human ageing." Scand. J. Immunol. 56(5): 518-521.

Shurin, M. R., G. V. Shurin, et al. (2007). "Aging and the dendritic cell system: Implications for cancer." Crit. Rev. Oncol. Hemat. 64(2): 90-105.

Solana, R., R. Tarazona, et al. (2012). "Innate immunosenescence: Effect of aging on cells and receptors of the innate immune system in humans." Seminars in Immunology 24(5): 331-341.

Souza, H. S., C. C. Elia, et al. (1999). "Expression of lymphocyte-endothelial receptor-ligand pairs, alpha4beta7/MAdCAM-1 and OX40/OX40 ligand in the colon and jejunum of patients with inflammatory bowel disease." Gut 45(6): 856-863.

Steger, M. M., C. Maczek, et al. (1996). "Morphologically and functionally intact dendriticcells can be derived from the peripheral blood of aged individuals." Clinical and Experimental Immunology 105(3): 544-550.

Steger, M. M., C. Maczek, et al. (1996). "Morphologically and functionally intact dendritic cells can be derived from the peripheral blood of aged individuals." Clin. Exp. Immunol. 105(3): 544-550.

Swain, S., K. Clise-Dwyer, et al. (2005). "Homeostasis and the age-associated defect of CD4 T cells." Semin Immunol 17(5): 370-377. 
Sydora, B. C., N. Wagner, et al. (2002). "beta7 Integrin expression is not required for the localization of T cells to the intestine and colitis pathogenesis." Clin. Exp. Immunol. 129(1): 35-42.

Tan, S. Y., L. L. Cavanagh, et al. (2012). "Phenotype and functions of conventional dendritic cells are not compromised in aged mice." Immunol. Cell. Biol. 90(7): 722-732.

Tesar, B. M., W. E. Walker, et al. (2006). "Nurine myeloid dendritic cell-dependent toll-like receptor immunity is preserved with aging." Aging Cell. 5(6): 473-486.

Toapanta, F. R. and T. M. Ross (2009). "Impaired immune responses in the lungs of aged mice following influenza infection." Resp. Res. 10(112): 1-19.

Uyemura, K., S. C. Castle, et al. (2002). "The frail elderly: role of dendritic cells in the susceptibility of infection." Mechanisms of Ageing and Development 123(8): 955-962.

Valenzuela, H. F. and R. B. Effros (2002). "Divergent telomerase and CD28 expression patterns in human CD4 and CD8 T cells following repeated encounters with the same antigenic stimulus." Clin. Immunol. 105(2): 117-125.

Wagner, N., J. Lohler, et al. (1996). "Critical role for [beta]7 integrins in formation of the gutassociated lymphoid tissue." Nature 382(6589): 366-370.

Wong, C. P., K. R. Magnusson, et al. (2010). "Aging is associated with altered dendritic cells subset distribution and impaired proinflammatory cytokine production." Exp. Gerontol. 45(2): 163169. 


\section{Figure legends}

Fig.1 In vitro study design. DC-enriched low density cells (LDCs) were collected from healthy young and older subjects and cultured in the presence or absence of LPS for 24h. After the incubation, some DCs were used for analysis of DC phenotype and cytokine production, and the remainder were used for DC-priming of T cells. T cells from healthy young or older subjects were co-cultured with young or older DCs for 5 days. The controls were DCs or T cells incubated only with medium.

Fig. 2 Gating strategy for DCs and T cells. (A) LDCs were gated in the FSC/SSC plot (upper). These gated cells were separated according to expression of Lineage cocktail (Lin contains anti-CD3, CD14, CD19 and CD20) and HLA-DR; DCs were positive to HLA-DR but negative to Lin (lower). (B) In the MLR culture, T lymphocytes were identified by anti-CD3 staining.

Fig.3 Effects of ageing on surface marker expression on DCs. Data are mean \pm SE for $n=8$ samples from each group. Data were normalized by the Johnson Transformation. There was a significant effect of LPS $(\mathrm{P}<0.01)$ on expression of all surface markers except CD86, but no effect of age (two-way ANOVA). Significant differences are denoted as ${ }^{\mathrm{a}} \mathrm{P}<0.05,{ }^{\mathrm{b}} \mathrm{P}<0.01$ relative to control for the same age group (post-hoc tests with Bonferroni correction).

Fig.4 Effects of ageing on intracellular cytokine production by DCs. (A) Representative intracellular cytokine production by DCs after superenhanced Dmax (SED) normalised subtraction. (B) Data are mean $\pm \mathrm{SE}$ for $\mathrm{n}=8$ samples from each group. Data were normalized by the Johnson Transformation. There was a significant effect of age $(\mathrm{P}<0.05)$ on expression of TNF- $\alpha$ and IFN- $\gamma$ and of LPS $(\mathrm{P}<0.001)$ on expression of all cytokines (two-way ANOVA). Significant differences are denoted as ${ }^{a} \mathrm{P}<0.05,{ }^{b} \mathrm{P}<0.01$ relative to control for the same age group (post-hoc tests with Bonferroni correction).

Fig.5 Effects of ageing on LPS/DC-induced proliferation of $\mathbf{T}$ cells. (A) Representative flow cytometric analysis of T cell proliferation in the absence of LPS/DCs and LPS/DC-induced proliferation of T cells. (B) $\%$ of $\mathrm{T}$ cells diving induced by LPS/DCs. Data are mean \pm SE for $n=8$ samples from each group. Data were normalized by the Johnson Transformation. There was a significant effect of age $(\mathrm{P}<0.05)$ and LPS/DC 
exposure $(\mathrm{P}<0.05)$ on $\mathrm{T}$ cell proliferation (two-way ANOVA). Significant differences are denoted as ${ }^{\mathrm{a}} \mathrm{P}<0.05$ relative to no DC control for T cell with the same age group (post-hoc tests with Bonferroni correction).

Fig.6 Effects of ageing on DC-induced CD25 expression on $\mathbf{T}$ cells. Data are mean \pm SE for $\mathrm{n}=8$ samples from each group. Data were normalized by the Johnson Transformation. There was a significant effect of ageing $(\mathrm{P}<0.05)$ on $\mathrm{CD} 25$ expression by $\mathrm{CD}^{+} \mathrm{T}$ cells and of $\mathrm{DC}$ exposure $(\mathrm{P}<0.05)$ on $\mathrm{CD} 25$ expression by both $\mathrm{CD}^{+}$and $\mathrm{CD}^{+}$young T cells (two-way ANOVA). Significant differences are denoted as $\mathrm{N}$ $\mathrm{P}<0.05$ relative to the no-DC controls for T cells within the same age group; ${ }^{\mathrm{D}} \mathrm{P}<0.05$ relative to DC-stimulated T cells (without LPS) within the same age group (post-hoc tests with Bonferroni correction).

Fig.7 Effects of ageing on DC-induced expression of integrin $\boldsymbol{\beta} 7$ on $\mathbf{T}$ cells. Data are mean \pm SE for $n=8$ samples from each group. Data were normalized by the Johnson Transformation. There was a significant effect of age $(\mathrm{P}<0.05)$ and treatment $(\mathrm{P}<0.05)$ on expression of integrin $\beta 7$ (two-way ANOVA). Significant differences are denoted as ${ }^{\mathrm{N}} \mathrm{P}<0.05$ relative to the no-DC control for $\mathrm{T}$ cells within the same age group; ${ }^{\mathrm{D}} \mathrm{P}<0.05$ relative to DC-stimulated T cells (without LPS) within the same age group (post-hoc tests with Bonferroni correction).

Fig.8 Effects of ageing on DC-induced intracellular cytokine production by $T$ cells. Data are mean \pm SE for $n=8$ samples from each group. Intracellular cytokine production was assessed, as described in Materials and Methods, within the $\mathrm{CD}^{+} \mathrm{T}$ cell population. Data were normalized by the Johnson Transformation. There was a significant effect of age $(\mathrm{P}<0.05)$ on expression of IL-12, IL-10, TGF- $\beta$ and IFN- $\gamma$ and treatment $(\mathrm{P}<0.05)$ on all cytokines except IFN- $\gamma$ on Young and Old T cells, and IL-12 on Young T cells (two-way ANOVA). Significant differences are denoted as ${ }^{\mathrm{N}} \mathrm{P}<0.05$ relative to the no-DC control for $\mathrm{T}$ cells within the same age group; ${ }^{\mathrm{D}} \mathrm{P}<0.05$ relative to DC-stimulated $\mathrm{T}$ cells (without LPS) within the same age group; ${ }^{\mathrm{T}} \mathrm{P}<0.05$ relative to $\mathrm{T}$ cells from older subjects for the same condition (post-hoc tests with Bonferroni correction). 